\title{
Sensorless Control of deep-sea ROVs PMSMs excited by Matrix Converters
}

\author{
B.S. Bhangu, P. Snary, C.M. Bingham and D.A. Stone \\ UNIVERSITY OF SHEFFIELD \\ Department of Electronic and Electrical Engineering, \\ University of Sheffield, Mappin Street, \\ Sheffield, S1 3JD, UK. \\ Tel.: $+44 /(0)-1142225195$ \\ Fax: $+44 /(0)-1142225196$ \\ E-Mail: b.bhangu@sheffield.co.uk \\ URL: http://www.sheffield.ac.uk
}

\section{Keywords}

Marine, Matrix Converter, Permanent magnet motor, Sensorless control, Vector control

\begin{abstract}
The paper reports the development of model-based sensorless control methodologies for driving PMSMs using matrix converters. In particular, experimental results show that observer-based state-estimation techniques normally employed for sensorless control of PMSMs using Voltage Source Inverters (VSIs) [1,2], can be readily exported to matrix converter counterparts with minimal additional computational overhead. Furthermore, zero speed start-up and speed reversal are experimentally demonstrated. Finally, the observer is designed to be fault tolerant such that upon detection of a broken terminal (phase fault), the PMSM remains operational and could be utilized to provide a limp-home capability.
\end{abstract}

\section{Introduction}

Manufacturers of work-class deep-sea ROV's, Fig.1(a), are increasingly looking towards the replacement of traditional hydraulic based drive systems and other auxiliary equipment such as robot arms, lighting, and cable-laying and burial equipment, by electric-based technologies $[3,4]$. Although electromagnetic machines have lower power density that their hydraulic counterparts, electrically based power units have the potential to offer significant system advantages in terms of higher reliability, reduced overall system mass, improved control dynamics and better energy efficiency [3,4]; the latter translating to a net reduction in mass and drag from the umbilical cable connection for power transmission from a surface ship.

During deep-sea operation of the ROV, buoyancy constraints and cooling issues make it highly desirable to operate power electronic drive systems in an oil-filled environment subject to the high ambient pressure (up to 400bar), as opposed to being housed in a thick-walled metallic pressure vessel subject to nominal atmospheric pressure (1bar). However, capacitors (particularly electrolytic types) and some industrial grade semiconductor devices are known to be extremely sensitive to pressure due to their construction, and can implode under pressures corresponding to $3000 \mathrm{~m}$ sea depth $(\approx 300 \mathrm{bar})$. As drive systems must withstand $\approx 300$ bar ambient, the components should ideally be able to withstand $1.33 \times$ this pressure $(\approx 400$ bar) to provide an operating safety margin on the system components. Tests investigating electrical and mechanical failure of the power electronic devices by subjecting commercial devices to target pressures in an oil-filled pressure chamber have been previously attained, resulting to several device failures [4]. For electric thruster actuators and servo systems, it is apparent that alternatives to industry 


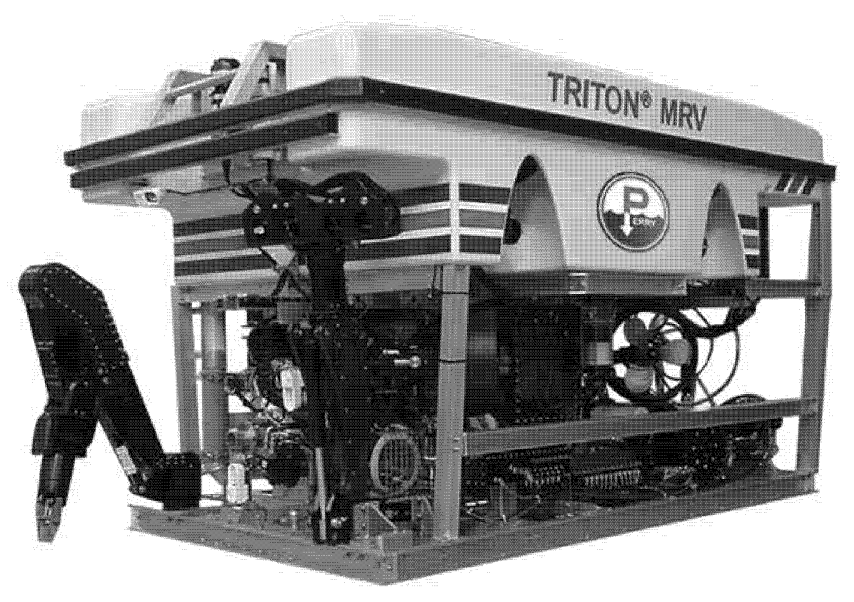

Fig. 1: (a) Deep-sea (3000m) Remotely Operated Vehicle (ROV) (Photograph courtesy of Perry Slingsby Systems)

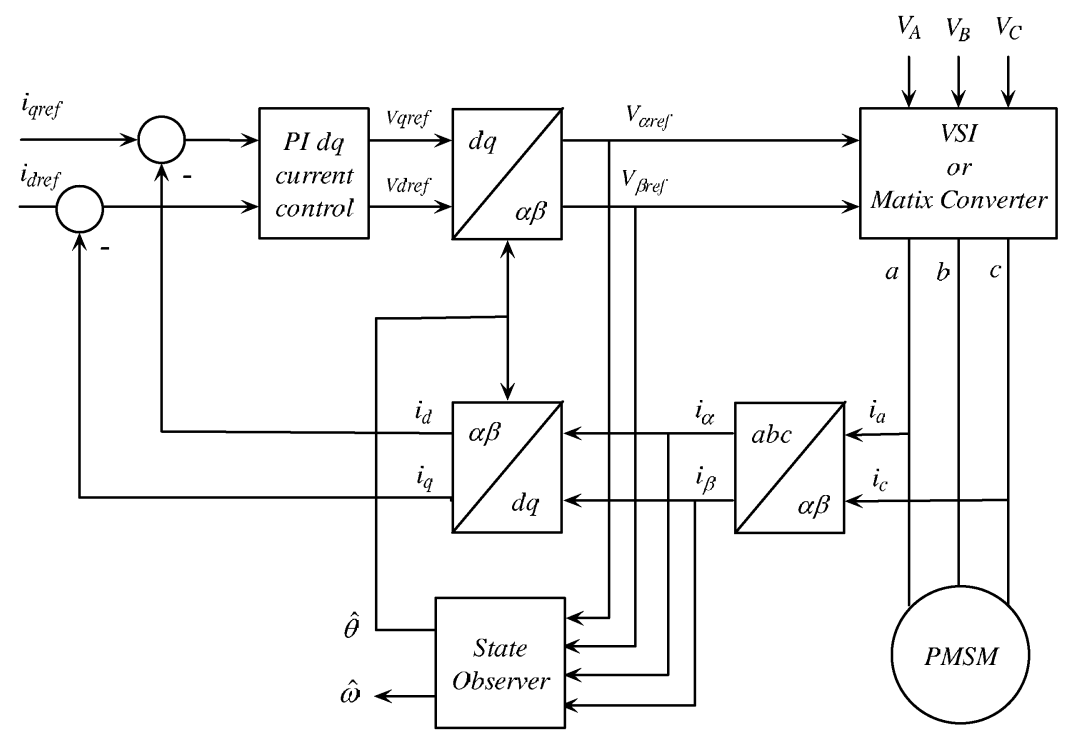

Fig. 2: Vector control scheme for PMSMs

standard Rectifier/Voltage Source Inverters (VSIs), and traditional AC/DC converters, are desirable, since these topologies require large reactive energy storage components (electrolytic capacitors being particularly pressure sensitive). Here then, matrix converters, $[3,5,6,7,8]$ present a natural candidate, since, unlike conventional rectifier/inverter counterparts viz. voltage- and current-source variants, converters based on a switch matrix do not require a two-stage (rectifier/inverter) conversion process, with the consequential elimination of the intermediate reactive energy storage element.

Moreover, by reducing the number of external wiring/connections between the motor and inverter by employing sensorless commutation of PMSMs, which traditionally require the use of encoder, resolver or Hall-effect signal feedback of rotor position, reliability can be improved further. The paper will show that by employing only measured motor terminal quantities and observer-based rotor position estimation schemes, no external sensor signal connections (between motor and inverter) are necessary, since the required current/voltage transducers (which operate satisfactorily in high-pressure oil-filled environments) 
can be sited at the power converter within the high-pressure chamber. Eliminating the shaft mounted position sensors also reduces vibration-damage susceptibility with a corresponding reduction in maintenance requirement. In addition, it is expected that by using such schemes on a typical all-electric work-class ROV, possessing $>6$ electric thruster actuators and $>6(\mathrm{~min})$ auxiliary servo motors, will ultimately result in a significant saving on connections/cable-mass. Furthermore, removing the necessity for an integrated rotor position sensor also simplifies the motor construction, since the special sealing requirements attributed to supporting correct operation of the sensor/electronics in the motor housing, in a harsh saline environment, are eliminated.

\section{Observer-based sensorless control of PMSMs using Matrix Converters}

For servo-type applications, and those where electromagnetic torque ripple can have a significant impact on overall product performance, vector control schemes, Fig. 2, are preferred, and sensorless operation must be achieved using only motor terminal quantities to accurately estimate the rotor position. Although control of PMSMs using matrix converters has been previously reported [3], only recently has sensorless operation of PMSMs with matrix converters attracted attention [5,6]. Furthermore, it will be shown that by suitable choice of matrix converter commutation strategy, observer-based sensorless control methodologies previously developed for sensorless control of PMSMs using 6-switch VSIs, can be conveniently employed in applications where PMSMs are excited by matrix converters. In this way, the

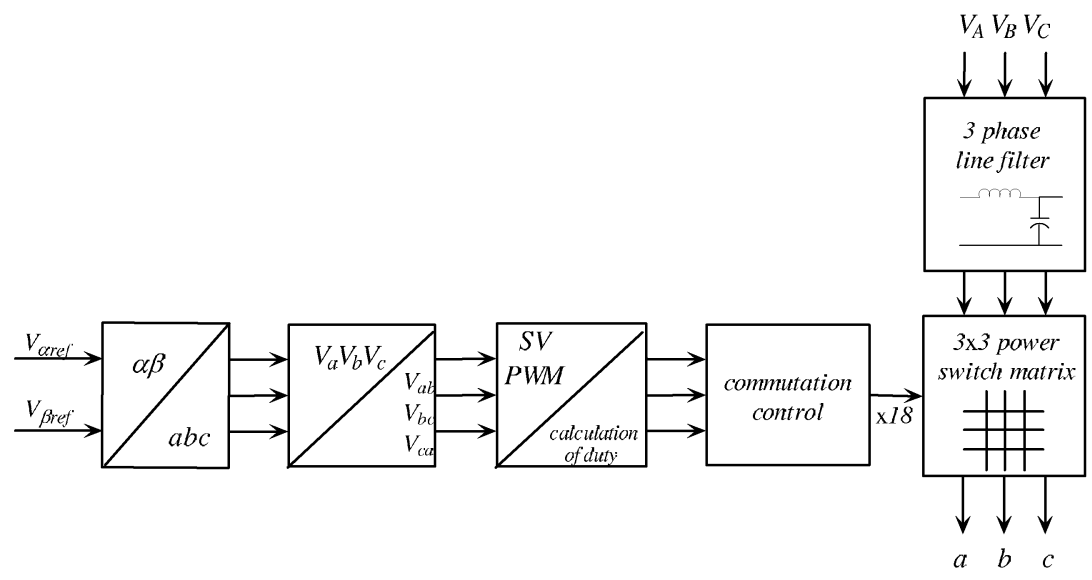

(a)

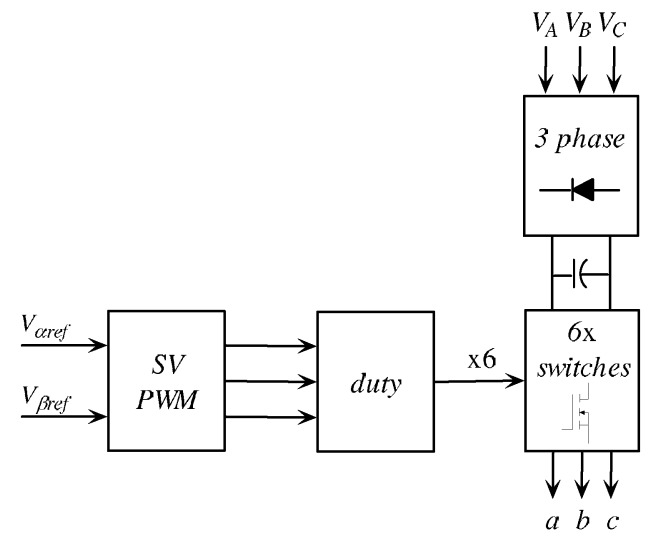

(b)

Fig. 3: Typical configuration of a 3x3 matrix converter including in-line filter components 


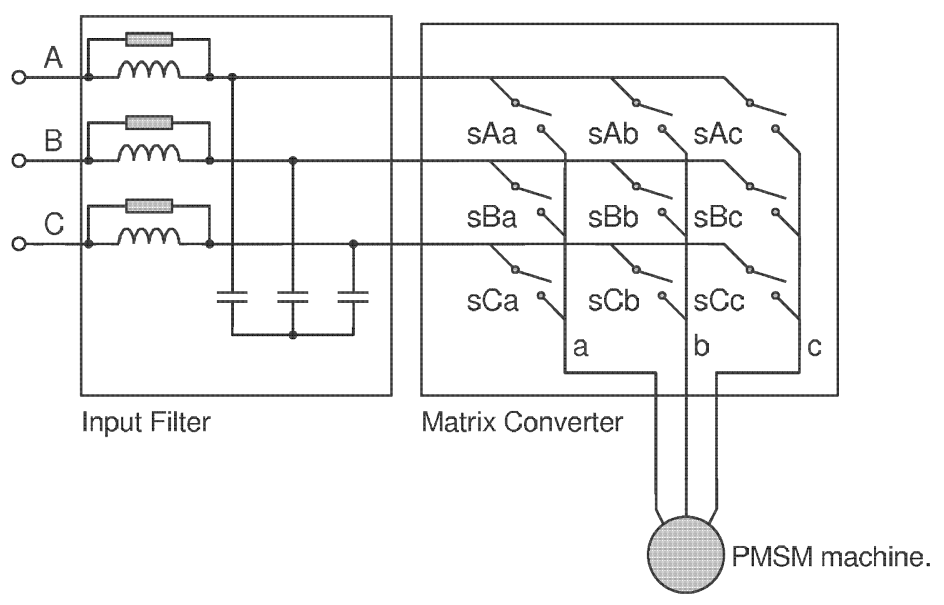

Fig. 4. Typical configuration of a $3 \times 3$ matrix converter including in-line filter components

additional benefits attributed to observer based techniques eg. convenient load-torque estimation for enhanced speed control, operation from zero speed and speed reversal are inherently accommodated [1,2].

The overall structure of a matrix converter based PMSM control scheme is shown in Fig. 3(a). By comparison with Fig. 3(b), the common requirement for control of PMSMs using 6-switch VSIs, and those of a matrix converter, can be seen. In particular, they both require knowledge of rotor position and demanded $V_{\alpha}$ and $V_{\beta}$, and feedback of motor phase currents. A typical configuration of a $3 \times 3$ matrix converter employed including in-line filter components, is shown by Fig. 4.

\section{Rotor position estimation in stator fixed reference frame}

An EKF is considered for sensorless estimation of rotor position for a PMSM powered by a matrix converter. A dynamic model of the PMSM in $\alpha \beta$ stator-fixed coordinates is considered:

$$
\begin{aligned}
& \frac{d}{d t} i_{\alpha}=-\frac{R_{s}}{L_{s}} i_{\alpha}+\frac{K_{e}}{L_{s}} \omega \sin \theta+\frac{v_{\alpha}}{L_{s}} \\
& \frac{d}{d t} i_{\beta}=-\frac{R_{s}}{L_{s}} i_{\beta}-\frac{K_{e}}{L_{s}} \omega \cos \theta+\frac{v_{\beta}}{L_{s}} \\
& \frac{d}{d t} \omega=\frac{K_{t} p}{J}\left(i_{\beta} \cos \theta-i_{\alpha} \sin \theta\right)-\frac{B}{J} \omega \\
& \frac{d}{d t} \theta=\omega
\end{aligned}
$$

where $R_{s}, L_{s}, K_{e}$ and $K_{t}$ are, respectively, the phase resistance, synchronous inductance, back-emf and torque constants; $J$ is the rotor inertia, $B$ is the motor viscous friction, $\omega$ is the rotor angular velocity, $\theta$ is the rotor position and $p$ denotes the number of pole pairs. Since only terminal quantities of the motor can be measured, the inputs are defined as $u=\left[v_{\alpha}, v_{\beta}\right]^{T}$, and the measured outputs are $y=\left[i_{\alpha}, i_{\beta}\right]^{T}$. A predictor-corrector scheme is employed to ultimately force the rotor position error to zero. However, it is seen from (1) that derivatives of currents are coupled by non-linear elements in terms of $\omega$ and $\theta$, and an EKF is considered for effective estimation of the state variables. The reader is directed to $[9,10]$ for complete formulation of the recursive EKF algorithm employed. 


\section{Experimental Results}

The presented matrix converter sensorless scheme has been employed to provide sensorless control of a $0.75 \mathrm{~kW}, 4$-pole PMSM with a base speed of 4000rpm. Measurements taken during steady-state operation of the machine with a speed demand of $418 \mathrm{rad} / \mathrm{s}(1000 \mathrm{rpm})$ are given in Fig. 5; specifically showing, rotor angular velocity, and importantly, the difference (error) between the measured and observed rotor position, respectively. The steady state position error is seen to be $\approx 0.2 \mathrm{rad}$. As demonstrated, the estimates are sufficiently accurate for the machine to adequately operate under closed-loop torque and speed control at steady-state.

An attractive feature of the EKF for this application is the ability to maintain observer stability at zero speed for start-up without incorporating any supplementary open-loop routines. By way of example, Fig. 6 shows measured results from the observer when the system is excited with a step demand from 0 to 209 $\mathrm{rad} / \mathrm{s}(500 \mathrm{rpm})$ at $\mathrm{t}=0 \mathrm{~s}$. As is evident, estimates of speed and position are accurately determined and stability is maintained with a steady-state position error of approx $\approx 0.2 \mathrm{rad}$. Moreover, it can be seen that for $\mathrm{t}<0 \mathrm{~s}$ zero speed of the observer estimates is maintained. Of note, however, is that position error significantly increases about zero speed, although the observer/controller combination does not show any destabilising tendencies.

Figure 7 , shows the response of the motor to a transient change in speed demand from $+209 \mathrm{rad} / \mathrm{s}$ to -209 $\mathrm{rad} / \mathrm{s}(+500 \mathrm{rpm}$ to $-500 \mathrm{rpm})$ at $\mathrm{t}=0 \mathrm{~s}$. It can be seen that the EKF accurately estimates the speed, Fig. 7(a). Although a slight increase of transient error in position estimates is evident, ultimately motor performance is not unduly degraded, Fig. 7(b).

A significant impediment to the general adoption of position sensorless control of the PMSM excited by matrix converters for applications on deep sea ROVs is the behaviour of the observer in response to a fault, ranging from faults due to damage to the umbilical resulting in input supply faults, to converter malfunctions and machine supply faults. Such conditions can provoke instability of the observer estimates that can be critical to matrix converter modulation schemes. Here then, fault tolerant implementation is proven, such that, upon occurrence of a motor open-circuit phase fault, from zero speed, the PMSM remains functional, and is transferred into a safe mode of operation. Figure 8(a) and (b) shows an example of a single phase machine terminal fault, indicated by the loss of supply to phase $\mathrm{B}$, and operated from start-up to steady-state $125 \mathrm{rad} / \mathrm{s}$ (300rpm). Phase voltage is monitored at the output terminal of the converter prior to the open circuit fault, hence, is included in the measurements. Upon detection of the fault the covariance matrices $\mathrm{Q}$ and $\mathrm{R}$ are modified such that stability of the observer estimates is retained. Figure $8(\mathrm{c})$ shows the rotor angular velocity whilst operating at 125rad/s (300 rpm), and the difference (error) between the measured and observed rotor position, respectively, where a steady state position error is seen to be $\approx 0.4 \mathrm{rad}$, Fig $8(\mathrm{~d})$. As demonstrated, the observer does not show any destabilizing tendencies and the estimated position remains sufficiently accurate for the machine to operate under closed-loop torque and speed control, ultimately allowing the ROV to accommodate a "limp-home" facility. Figure 8(e) shows the measured and estimated currents in the stator fixed reference frame. 


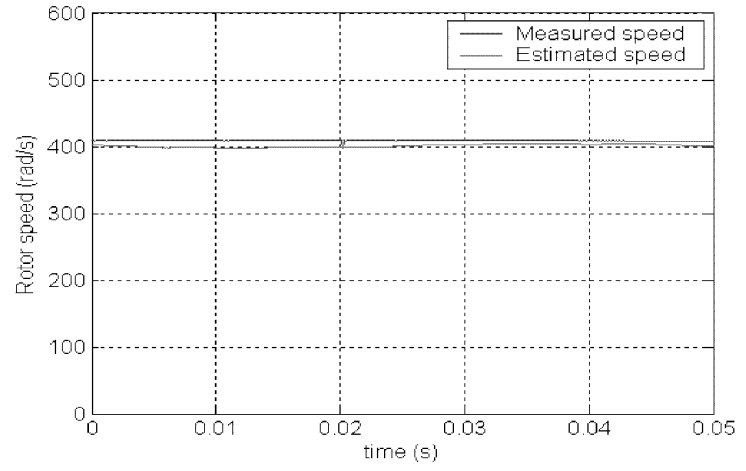

(a)

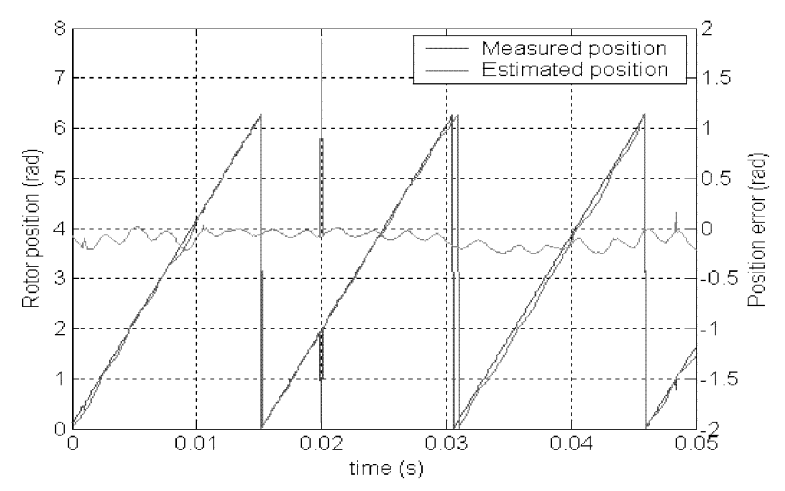

(b)

Fig. 5: Observer-based vector control of PMSM at $418 \mathrm{rad} / \mathrm{s}$ (1000 rpm) (a) Measured and estimated speed (b) Measured and estimated rotor position and position error

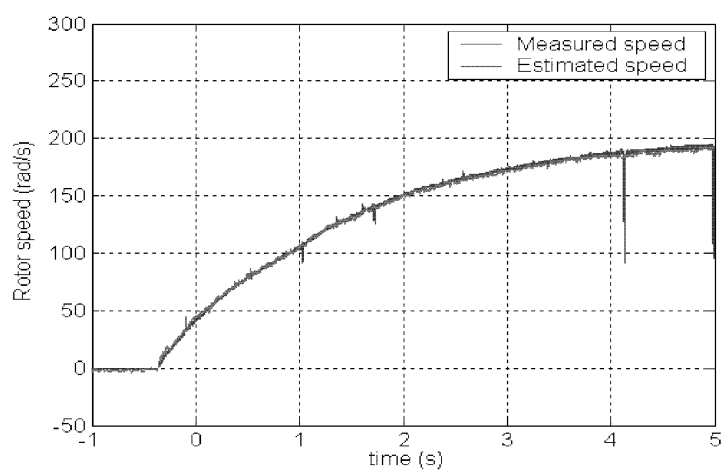

(a)

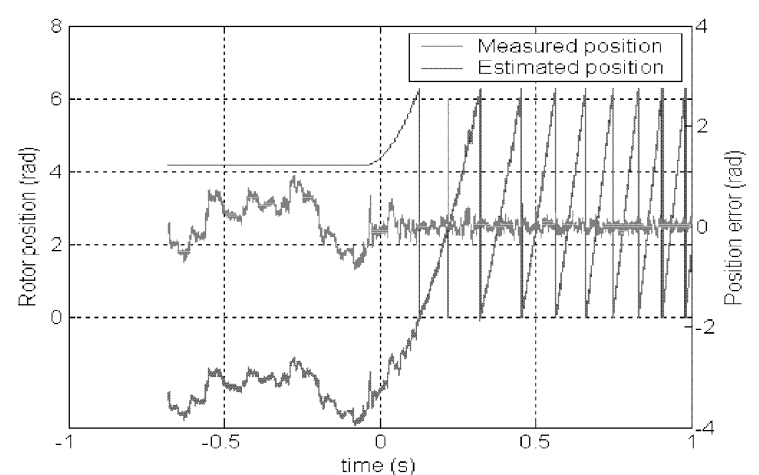

(b)

Fig. 6: Zero speed start-up to step demand of $209 \mathrm{rad} / \mathrm{s}(500 \mathrm{rpm})$ at $\mathrm{t}=0 \mathrm{~s}$ (a) Measured and estimated speed (b) Measured and estimated rotor position and position error

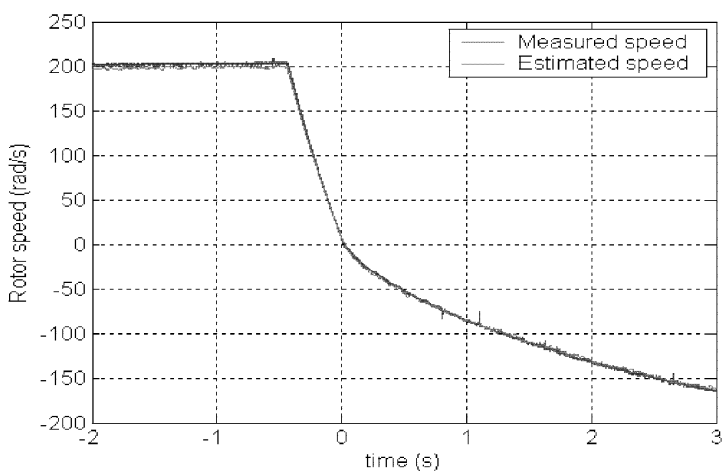

(a)

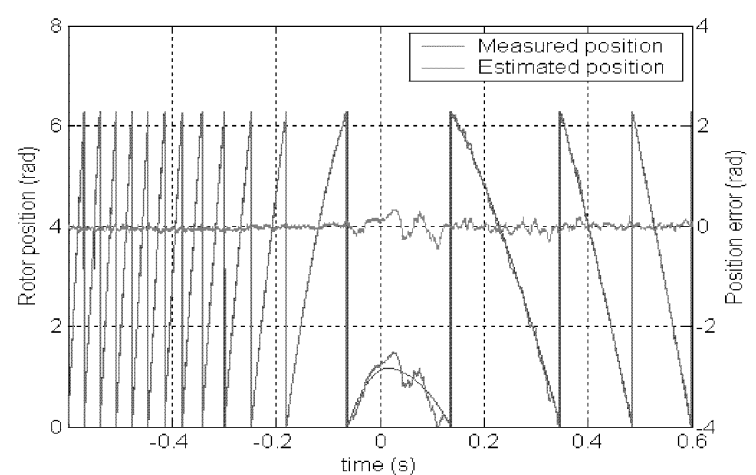

(b)

Fig. 7: Measured results of dynamic acceleration through zero-speed from $209 \mathrm{rad} / \mathrm{s}$ to $-209 \mathrm{rad} / \mathrm{s}(+500$ to $-500 \mathrm{rpm}$ ) (a) Measured and estimated speed (b) Measured and estimated rotor position and position error 


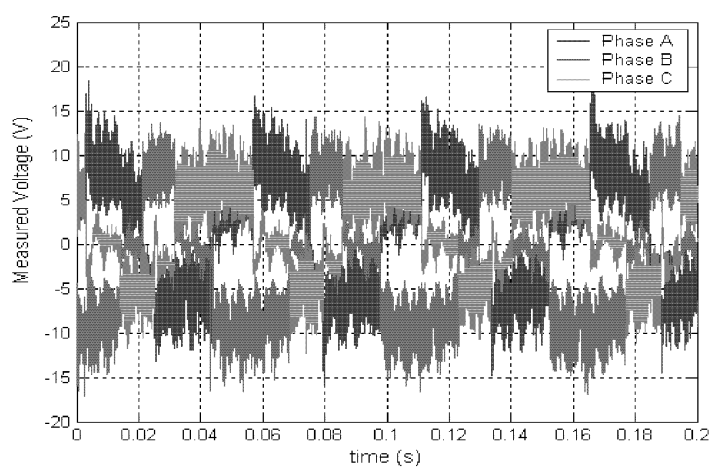

(a)

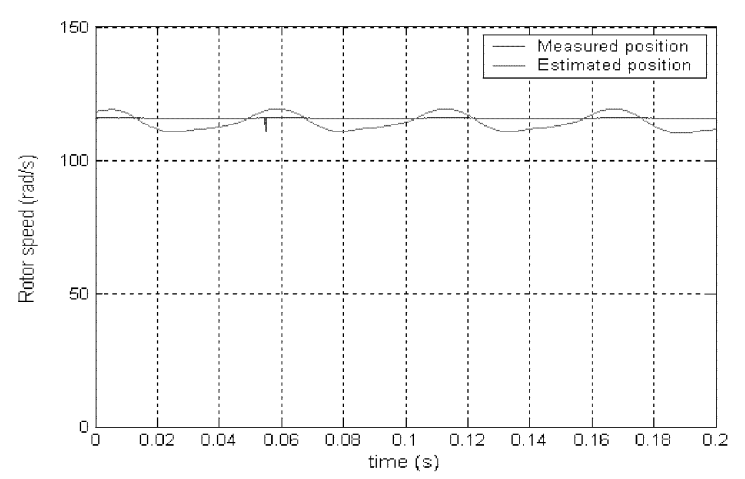

(c)

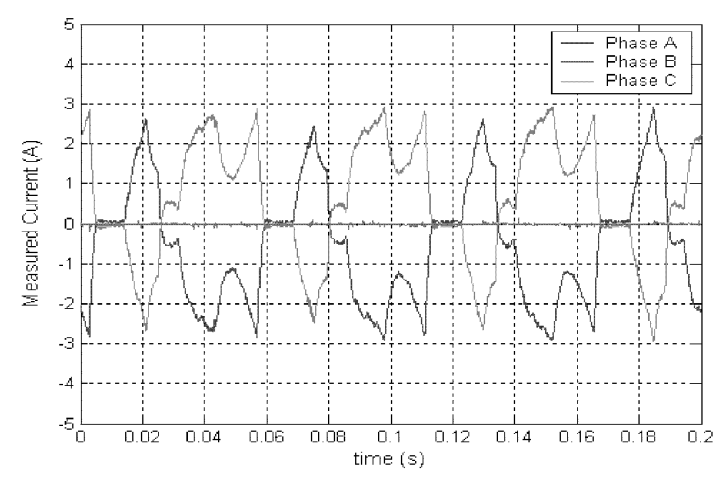

(b)

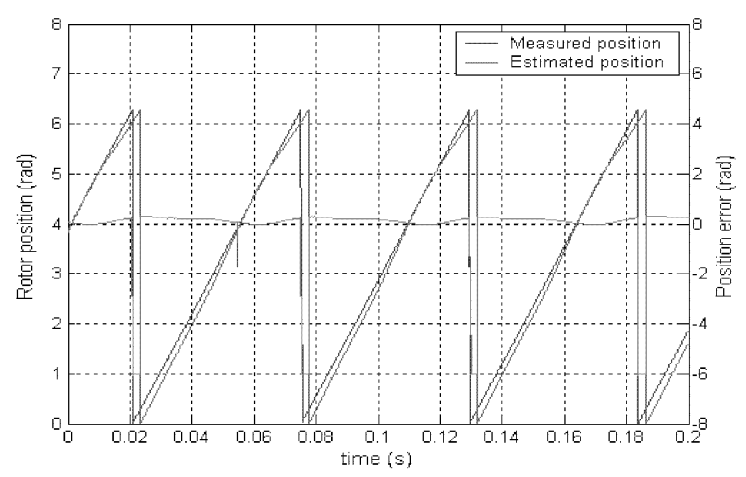

(d)

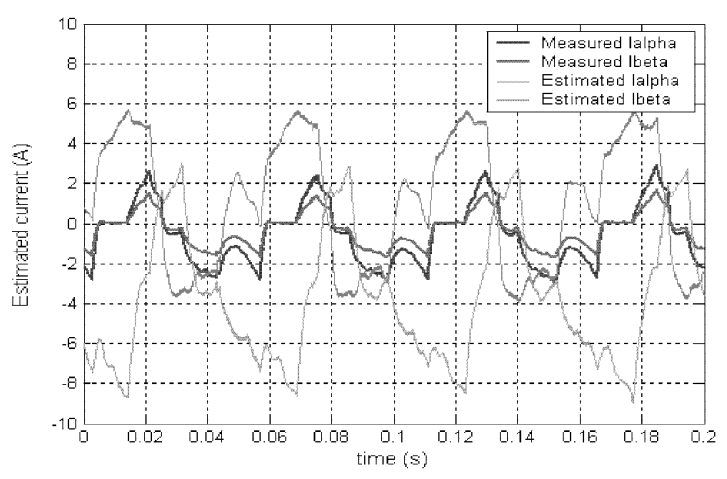

(e)

Fig. 8: Response of observer based technique to a phase fault (loss of Phase B) whilst operating at $125 \mathrm{rad} / \mathrm{s}$ (300 rpm) (a) Measured phase voltages (b) Measured phase current (c) Measured and estimated speed (d) Measured and estimated rotor position and position error (e) Measured and estimated $\alpha \beta$ axis currents. 


\section{Conclusion}

The implementation of $3 \times 3$ matrix converter for the application of deep-sea ROVs, where systems are expected to sustain operation at high ambient pressures, up to 300bar, commensurate with operation of ROVs at $3000 \mathrm{~m}$ is reported. The conventional voltage source inverter (VSI) which traditionally facilitates most synchronous machine drives in industry applications, consist of large dc-link electrolytic capacitors, that cannot withstand the considered pressures unless enclosed in large air-filled chambers at atmospheric pressure, which tends to be of high mass. Here, excitation of PMSMs via matrix converters, which eliminates large dc-link capacitors, provides an alternative solution. In particular, with a view to minimising external cabling/routing requirements, and simplifying motor designs by virtue of not having to house and seal rotor position sensors and associated electronics in the motor housing, sensorless operation of PMSM excited by $3 \times 3$ matrix converter is reported. It is shown that observer-based sensorless schemes, developed for control of PMSMs with traditional VSIs, can be readily applied to variants driven matrix converters, with experimental results showing the benefits of employing such schemes. Start-up from zero speed and speed reversal are experimentally demonstrated. Finally, a degree of fault tolerant operation is demonstrated, such that upon occurrence of a phase fault, the PMSM remains functional, and the stability of the observer is maintained.

\section{References}

[1] Bhangu, B. S., Williams, C., Bingham, C. M., Coles, J.: 'Nonlinear state-observer techniques for sensorless control of automotive PMSMs, including load torque estimation', Proc. EPE 2003, Toulouse, France, CD-ROM Proceedings.

[2] Bhangu, B. S., Williams, C., Bingham, C. M., Coles, J.: 'EKFs and other Nonlinear State-Estimation Techniques for Sensorless Control of Automotive PMSMs', SPEEDAM 2002, Italy, p. C5, 33-38.

[3] Bouchiker, S., Capolino, G. A., Poloujadoff, M.: 'Vector Control of a Permanent-Magnet Synchronous Motor Using AC-AC Matrix Converter', IEEE Trans. on Power Electronics, Vol. 13, No. 6, November 1998.

[4] Snary. P., Bingham, C. M., Stone, D. A., and Schofield, N.: 'Commercial Electronic Devices for Operation in High-Pressure Deep-Sea Drive Systems', PCIM 2001, Nurnberg, Germany.

[5] Tain Hua Liu, Szu Han Chen, Der Fa Chen: 'Design and Implementation of A Matrix Converter PMSM Drive Without A Shaft Sensor', IEEE Trans. on Aerospace and Electrical Systems. Vol. 39, p.228-43, January 2003.

[6] Der-Fa-Chen, Tian-Hua-Liu, Szu-Han-Chen: 'Implementation of a novel sensorless matrix converter PMSM drive', 4th-IEEE International Conference on Power Electronics and Drive Systems. IEEE PEDS 2001 Indonesia, CD-ROM Proceedings.-No 2001: 718-24 Vol.2.

[7] Wheeler, P. W., Rodriguez, J., Clare, J. C., Empringham, L., Weinstein, A.: 'Matrix converters: a technology review', IEEE Trans. on Industrial Electronics. Vol. 49, No. 2, pp.276-88, April 2002.

[8] Huber, L., Borojevic, D.: 'Space Vector Modulated Three-Phase to Three Phase Matrix Converter with Input Power Factor Correction', IEEE Trans. on Industrial Applications, Vol. 31, No. 6, 1995.

[9] Kalman, R. E.: 'A new approach to linear filtering and prediction problems', Trans. of the ASME - Journal of Basic Engineering, Series D, pp 35-45, 1982.

[10] Bado, A., Bolognani, S., Zigliotto, M.: Effective estimation of speed and rotor position of a PM synchronous motor drive by a Kalman filtering technique. Proc. of IEEE Power Electronics Specialist Conference, pp.951$957,1992$. 